\title{
Donor retention in health care in Iran: a factor analysis
}

\author{
Sara Aghababa ${ }^{1}$, Amir Ashkan Nasiripour ${ }^{1}$, Mohammadreza Maleki²*, Mahmoodreza Gohari ${ }^{3}$
}

\begin{abstract}
Background: Long-term financial support is essential for the survival of a charitable organization. Health charities need to identify the effective factors influencing donor retention.

Methods: In the present study, the items of a questionnaire were derived from both literature review and semi-structured interviews related to donor retention. Using a purposive sampling, 300 academic and executive practitioners were selected. After the follow- up, a total of 243 usable questionnaires were prepared for factor analysis. The questionnaire was validated based on the face and content validity and reliability through Cronbach's $\alpha$-coefficient.

Results: The results of exploratory factor analysis extracted 2 factors for retention: donor factor (variance $=33.841 \%$; Cronbach's $\alpha$ coefficient $=90.2$ ) and charity factor (variance $=29.038 \%$; Cronbach's $\alpha$-coefficient $=82.8$ ), respectively. Subsequently, confirmatory factor analysis was applied to support the overall reasonable fit.

Conclusions: In this study, it was found that repeated monetary donations are supplied to the charitable organizations when both aspects of donor factor (retention factor and charity factor) for retention are taken into consideration. This model could provide a perspective for making sustainable donations and charitable giving.
\end{abstract}

Keywords: Charitable Giving, Donor, Retention, Factor Analysis, Health care

Copyright@ Iran University of Medical Sciences

Cite this article as: Aghababa S, Nasiripour AA, Maleki M, Gohari M. Donor retention in health care in Iran: a factor analysis. Med J Islam Repub Iran. 2017 (17 Feb);31:13. https://doi.org/10.18869/mjiri.31.13

\section{Introduction}

Health care industry needs an effective intervention in its financial system because of the deficiency in covering the increasing costs (1). These increasing costs show the burden of health care financing, which results in out-ofpocket payments. Unfortunately, out-of-pocket expenses become a considerable proportion of the total expenditure on health care, increasing the probability and risk of facing catastrophic payments for the households in Iran. This issue leads to more severe problems in the households with lower incomes. However, any kinds of subsidies and support could be a good solution (2) to reduce the effect of catastrophic expenditure (3).

Charitable giving was introduced as a world financing scheme by World Health Organization (4), which included the least proportion of health expenditure in healthcare in Iran (5). However, few scientific studies have been pub-

\section{Corresponding author:Dr Mohammadreza Maleki,maleki.mr@iums.ac.ir}

1. Department of Health Services Management, Science and Research Branch, Islamic Azad University, Tehran, Iran.

2. Department of Health Service Management, School of Health Management and Information Sciences, Iran University of Medical Sciences, Tehran, Iran.

3. Department of Biostatistics, Iran University of Medical Sciences, Tehran, Iran. lished about this issue in Iran. Indeed, the trend of publications has been increasing in the recent years. In this regard, academic cooperation with research centers should be increased (6), whereas academics deal with the concept of charitable giving in a variety of disciplines from different perspectives worldwide (7). Nonetheless, one of the most important issues in implementing a health care financing system is the sustainability of the available resources (8).

Retaining donors is becoming a critical problem for keeping donors (9). Practically, this attrition has been considered as a main concern for charitable organizations (10). A definition of donor retention is provided by Royce (11): "Donor retention does exist if within a specified period, an individual voluntarily and repeatedly acted in favor of an organization and intends to continue to do so

$\uparrow$ What is "already known" in this topic:

Financial pressure and changes in work and personal conditions play a crucial role in withdrawing from charitable giving by donors. Recently, there are efforts to increase the contribution of charitable giving by Deputy Office of Social Affairs at Iran Ministry of Health and Medical Education.

$\rightarrow$ What this article adds:

Charity organizations should be active in fundraising and retaining for consistency over the time. However, lack of a database for the charitable giving and donors in Iran has limited the research in this area. 
in the future." In fact, retention is a behavioral pattern of donors to a charity (12). Findings indicate that numerous charity organizations lose more than half of their donors within the first year after they have been attracted to the institution (13). The sudden tendency toward donors and the abrupt withdrawal from it have been observed globally (14).

However, the academic community has not paid due attention to the factors influencing the tendency of people to continue their contributions (15). Apparently, financial pressure and changes in work and personal conditions play a crucial role in withdrawing from charitable giving by donors $(16,17)$. Earlier studies have focused on the variables influencing donor retention. Sargeant and Hudson (16) identified the factors appearing to influence donor attrition, which are as follow: trust, commitment, perceptions, communications, satisfaction, pressure, and gap sources. Also, Naskrent and Siebelt (18) showed the positive influence of commitment, trust, satisfaction, and involvement on donor retention. Positive experience and affinity with the charitable organization, donors' trust in the organization, and positive reputation of the charitable organization, as the determinants of donors' intention to repeat their donations, have been outlined by Beldad, Snip (15). Bennett (19) indicated the "lifetime durations" that a donor remained with a charitable organization. Donor loyalty model in charitable giving consisting of passive and active commitment has been designed by Sargeant and Woodliffe (20). In this method, charities could manage and communicate the long-term relationship between donors and beneficiaries (17).

Nonetheless, these previous studies, which have implicitly confirmed donor and charity factors associated with donor retention, have not categorized variables into specific factors. Moreover, the evidence of donor retention in Iran's health care system is scarce. Recently, the efforts have been done to increase the contribution of charitable giving by Ministry of Health and Medical Education. The Deputy Office of Social Affairs has been recently added to the organizational chart of the Ministry of Health and Medical Education to work along with other wellstablished deputy offices. This restructure can play an increasingly important role in policy making. Therefore, the findings of the present study may help the deputy of social affairs in Ministry of Health and Medical Education to manage charitable giving by donor retention. Thus, this study aimed at determining items and effective factors associated with donor retention in health care charities in Iran.

\section{Methods}

This cross sectional survey was conducted on the health care system of Iran to identify factors affecting donor retention.

\section{Questionnaire}

A questionnaire was developed to identify the importance of items affecting the retention of donors in health care system in Iran. Therefore, a process entailing qualitative and quantitative approaches was undertaken.
The questionnaire items for the quantitative part were derived from both the literature review and 8 semi-structured interviews with key informant experts (qualitative part). The experts selected both academic and experimental knowledge relating to health care charities. These participants constituted an appropriate sample because they were extremely familiar with health care and charity. The designed questionnaire included 2 parts: demographic data (including age, sex, educational level, and working experience); and 12 items associated with donor retention. A 5point Likert scale $(1=$ strongly disagree to $5=$ strongly agree) was used as the response format to evaluate the effect of each item on the retention. A high score in an item indicated the effectiveness of that item on the retention. To clarify the survey for the respondents and to gain higher responding rates, a short introduction was used at the beginning of the questionnaire.

Academic experts in this domain confirmed that the questionnaire had appropriate content for face validity. Only minor changes were needed and implemented by these 8 experts. Moreover, content validity was assessed among 8 key experts; the total CVR (Content Validity Ratio) (21) and CVI (Content Validity Index) (22) were 0.95 and 0.96 , respectively. None of the preliminary items was eliminated from the questionnaire. To examine the internal consistency of the scale, Cronbach's $\alpha$-coefficient was calculated for each extracted factor; additional detailed information presented in the full report (23).

\section{Sampling}

To find appropriate participants, a purposive sample of 300 practitioners was selected. This sample was recruited based on the participants' academic and executive experience in charitable giving. The questionnaire was distributed to all provinces of Iran in health care charities. Data were collected through anonymous self-administrated questionnaires. After the follow- up, a total of 243 usable questionnaires were received (response rate of $81 \%$ ). This process lasted more than 5 months.

\section{Statistical Analysis}

Questionnaires were coded for data analysis. EFA (Exploratory Factor Analysis) was used to evaluate all the items. In addition, statistical analyses were executed by SPSS v.22, except for CFA (Confirmatory Factor Analysis), which was carried out by LISREL V.8.54. Varimax rotation was used to reduce the items; and Kaiser-MeyerOlkin (KMO) and Bartlett's test were computed. Furthermore, content validity and reliability (Cronbach's $\alpha$ coefficient) were computed using the Microsoft Excel and SPSS v.22, respectively.

\section{Ethical Considerations}

This research was derived from a $\mathrm{PhD}$ dissertation and was approved by Islamic Azad University (code no: 3663). All respondents were informed about the purpose and necessity of the study and were assured of data confidentiality, then, they filled the questionnaire voluntarily.

\section{Results}

A total of 243 individuals participated in this study. 
Table 1. Respondents' Demographic Characteristics $(\mathrm{n}=243)$

\begin{tabular}{|c|c|c|c|}
\hline Variable & Category & $\mathrm{n}$ & $\%$ \\
\hline \multicolumn{4}{|l|}{ Sex } \\
\hline & Male & 154 & 63.37 \\
\hline & Female & 89 & 36.6 \\
\hline \multicolumn{4}{|c|}{ Age group (year) } \\
\hline & $<30$ & 41 & 16.87 \\
\hline & $31-40$ & 86 & 35.39 \\
\hline & $41-50$ & 67 & 27.57 \\
\hline & $>51$ & 49 & 20.16 \\
\hline \multicolumn{4}{|c|}{ Educational level } \\
\hline & Diploma & 10 & 4.11 \\
\hline & Associate & 23 & 9.46 \\
\hline & Bachelor & 122 & 50.20 \\
\hline & Master & 65 & 26.74 \\
\hline & $\mathrm{PhD}$ & 23 & 9.46 \\
\hline \multicolumn{4}{|c|}{ Work experience(year) } \\
\hline & $<10$ & 134 & 55.14 \\
\hline & $10-20$ & 65 & 26.74 \\
\hline & $21-30$ & 26 & 10.69 \\
\hline & $>30$ & 18 & 7.40 \\
\hline
\end{tabular}

About $63 \%(n=153)$ of the respondents were males. Most participants $(36 \%)$ aged 31 to 40 years, and half of them $(n=121)$ had a bachelor's degree; moreover, more than half of the participants had less than 10 years of work experience $(55 \%)$. The respondents' demographic characteristics are summarized in Table 1.

Initially, Kaiser-Meyer-Olkin was computed to show the sample adequacy (0.91), and Bartlett's test of independence was conducted to establish the correlation matrix $(\chi 2$ $=1620.726 ; \mathrm{p}<0.001)$.

In addition, varimax rotation was used to reduce the data. Factors that had an eigenvalue greater than 1 were retained. Then, 2 factors were extracted from EFA. Factor 1 included 7 items and was labeled as donor factor for retention; factor 2 included 5 items and was named charity factor for retention. Table 2 demonstrates factor names, ei- genvalues, explained variances, the items compromising each factor, and factor loading of each item. In addition, Table 2 displays Cronbach's $\alpha$-coefficient of 90.2 for Factor 1 , and 82.8 for Factor 2.

The findings, based on CFA, were compared with the recommended cutoff values proposed by $\mathrm{Hu}$ and Bentler (24):

Chi-square divided the degree of freedom ratio $\left(\chi^{2} / \mathrm{df}\right.$ $=2.55$ ), standardized root mean square residual (RMSEA $=0.080)$, incremental fit index (IFI $=0.98)$, normed fit index $(\mathrm{NFI}=0.97)$, non-normed fit index $(\mathrm{NNFI}=0.97)$ and comparative fit index $(\mathrm{CFI}=0.98)$. In general, the findings support the final proposed model.

Table 2. Results of exploratory factor analysis for the two factors of donor retention

\begin{tabular}{lcc}
\hline Factors/Items & Statements of the Items & Loading \\
\cline { 2 - 3 } Factor 1: Donor Factor for Retention & Factor2 \\
Eigenvalue = 6.301; Variance $=33.841 \%$; Cronbach's $\alpha$-coefficient $=90.2$ & 0.822 \\
DR4 $\quad$ Connection & 0.807 \\
DR7 & Positive feedback & 0.792 \\
DR2 & Satisfaction & 0.787 \\
DR5 & Motivation & 0.670 \\
DR6 & Altruism & 0.573 \\
DR1 & Incentives & 0.280 \\
DR3 & Celebrations & 0.570 \\
Factor 2: Charity Factor for Retention & 0.181 \\
Eigenvalue $=1.245 ;$ Variance=29.038\%; Cronbach's $\alpha$-coefficient $=82.8$ & 0.236 \\
DR10 & Membership & 0.331 \\
DR11 & Specified and short period of time & 0.521 \\
DR9 & reminder frequency & 0.147 \\
DR8 & Solicitation methods & 0.143 \\
DR12 & Lobbying & 0.403 \\
\hline
\end{tabular}

Note. $D R=$ Donor Retention

Table 3. Summary of fit statistics from confirmatory factor analysis and recommended values

\begin{tabular}{lllllll}
\hline Model & $\chi^{2} / \mathrm{df}$ & RMSEA & IFI & NFI & \multicolumn{1}{l}{ NNFI } \\
\hline CFA & 2.55 & 0.080 & 0.98 & 0.97 & 0.97 \\
Criteria & $3>\chi^{2} / \mathrm{df}>1$ & $<0.08$ & $>0.95$ & $>0.90$ & 0.98 \\
\hline
\end{tabular}

Note. $\chi^{2}$ df: Chi-square divided degree of freedom ratio, RMSEA: Standardized Root Mean Square Residual, IFI: Incremental Fit Index, NFI: Normed Fit Index, NNFI:

Non-Normed Fit Index, CFI: Comparative Fit Index. 


\section{Discussion}

The present study aimed at identifying factors related to the retention of donors in health care system of Iran. The effective factors and variables for the donor retention are recognized in 2 categories: donor factor for retention and charity factor for retention. Shelley and Jay Polonsky (25) indicated processing determinants which were categorized into donor experience of contribution. This led to future donations and could increase loyalty through time.

\section{Factor 1: Donor factor for retention}

An effective relationship and connection between charities and donors results in donor retention (16). Similarly, the good quality of communication between charities and donors raises charitable giving (15). Indeed, to have a regular communication with donors, charities should understand the future needs and preferences of donors (13). The results of another study revealed that for financial support in long-term charitable giving, donors want to stay in touch with the sponsored child (17). Likewise, acknowledgement mechanisms play an important role in this issue(9). Hence, sponsoring a patient could be developed in the health care industry. Our findings demonstrated that the close connection between organizations and donors was the most important item to increase sustainable charitable giving.

One of the reasons why donors leave the charity was the lack of positive feedback and unawareness of the ways the charitable giving was spent (16). Ward and Mckillop (26) pointed out that donors' resource management and retention improvement were made possible by providing good feedback practice of volunteers in Ireland. In other words, quality of services provided to the donors and informing them of the effect of their giving highly affected their retention (27). Thus, receiving positive feedback for the charitable giving and observing the direct effect of the contribution, encourage the donors to continue their cooperation and contribution to the charity organizations.

Naskrent and Siebelt (18) found that satisfaction, as a variable, indirectly influenced donor retention in Germany. The role of satisfaction was consistent with the findings of earlier studies $(15,28,29)$. Consequently, personal satisfaction is one of the crucial variables for the donors to persist in their charitable giving.

Peachey, Lyras (30) revealed that themes related to the motivation of volunteers in a sport field finally lead to their retention. This study focused on volunteers who donated their time, but not their money. Hence, the incentives of the donors have to be taken into consideration. Policy makers of the charities have to illustrate different means of contribution corresponding to the different motives of the donors.

Altruism is a powerful sense, which has no limitation, and it is an endless intrinsic motivation of a donor to donate to a charity (31). Donors choose to be helpful in a charitable organization out of altruism. They care about and help others even though this sense brings no benefit to them. Therefore, policymakers can consider how to utilize this great potential behavior.

In many countries, charitable donations are deducted from taxes and this could be an incentive for donors. Thus, designing appropriate tax policies could attract and retain donors (32). Many individuals, commercial firms, and trading companies have a twofold benefit in doing such deeds: charitable actions and tax exemption. Moreover, other incentives motive donors to provide ongoing support to the charitable organizations.

Holding an appreciation ceremony is an effective variable for the donor retention. Paying attention to this variable would increase charitable contributions in the long term (33). Moreover, a thank-you letter from a needy patient can be a reason for sustainability of the charitable donations.

\section{Factor 2: Charity factor for retention}

Belonging to a charity, like being a member of that organization, is associated with willingness to donate continuously (34). Developing a comprehensive database can be useful (35). Besides, providing an ID card makes a kind of commitment and obligation to frequently donate to a charity in the future. Providing such guarantee could be a helpful strategy for charity managers to gain continuation of the donors' support. However, in an unorganized system with a weak supervision, the possible misuses of the card should also be considered; and this is why some institutions refrain from providing this card.

Likewise, providing the chance of donation in different times could make a long-term supportive relationship with more donors. However, short deadlines could enhance charitable giving (36). In fact, extending the deadlines for the donors is stated as decreasing the income of the charity organizations.

According to Breman (36), the frequency of reminding the donors to contribute to the institutes raises their retention. She stated that monthly donors are the best ones for the charities. Therefore, time track strategies are highly useful and charities could design a reminder media to maintain donors. A charitable organization has to plan for reminders by SMS on cellphones, email, and telephone.

Solicitation methods of a charitable organization include telephone, direct mail, letter, social media and could influence the retention of donors. However, the donors are the decision makers (37) and their positive word of mouth (38) have been the most fundamental factor in their retention. The findings of this study revealed that the effort of the charity organizations and adding variety to their solicitation methods would give rise to the response rate of the donors, particularly those who have had experience in volunteering or charitable donations. Hence, the effort of the organizations and their use of diverse solicitation methods can be effective.

According to Olsen and Eidem (39), lobbying can be a fundraising activity, which is a potential factor for generating more revenue, and reduces donors attrition (16). Therefore, charities could increase their lobbying power to retain the donors.

\section{Limitations}

This was only the first stage in understanding the underlying factors. The items were developed through a careful 
literature review and interviews with key informant experts, so future research should gather additional data in donor retention items. Additionally, this single construct model requires more tests by replications in different situations.

\section{Conclusions}

The findings of this study presented a broad range of variables playing substantial roles in donor retention. The factor grouping elucidates the important role of charities in fundraising and retaining activities (charity factor for retention) and also the important role of intervention in reinforcing donors for retaining (donor factor for retention). Therefore, charities should be sensitive to both factors for consistency over the time. These identified issues could shed light on how to retain donors in health charities. Suggestions provided in this paper could enhance the competitive advantage of the charities.

Unfortunately, lack of a database for the charitable giving and donors in Iran limited the research in this area. Despite this, authors suggest this fruitful field for the future research, especially in the health care industry. Further research is needed to explore the effect of social marketing in donor retention, future studies in donor retention, qualitative studies of donor retention, the reason of on-off donation, and termination of donors' support, and the effect of donor retention on health systems revenue. These studies can have positive impacts on charitable organizations and guide the experimental field of charitable giving in health care.

\section{Acknowledgement}

The authors would like to thank the practitioners who devoted their time to filling out the questionnaire and being involved in the interview

\section{Conflict of Interests: None declared.}

\section{References}

1. Erwick DM, Nolan TW, Whittington J. The triple aim: care, health, and cost. Health Affairs. 2008;27(3):759-69.

2. Hajizadeh M, Nghiem HS. Out-of-pocket expenditures for hospital care in Iran: who is at risk of incurring catastrophic payments? Int J Health Care Finance Econ. 2011;11(4):267-85.

3. Kavosi Z, Keshtkaran A, Hayati R, Ravangard R, Khammarnia M. Household financial contribution to the health System in Shiraz, Iran in 2012. Int J Health Policy Manag. 2014;3:243-9.

4. OECD., Eurostat., WHO. A System of Health Accounts. 2011 ed: OECD Publishing.; 2011.

5. Zakeri M, Olyaeemanesh A, Zanganeh M, Kazemian M, Rashidian A, Abouhalaj $\mathrm{M}$, et al. The financing of the health system in the Islamic Republic of Iran: A National Health Account (NHA) approach. Med J Islam Repub Iran. 2015;29:243.

6. Aghababa S, Maleki MR, Gohari MR. Narrative Review of Studies on Charity in Health Care, Iran. Hakim Res J. 2015;17(4):329-36.

7. Bekkers R, Wiepking P. A literature review of empirical studies of philanthropy: Eight mechanisms that drive charitable giving. Nonprofit and Voluntary Sector Quarterly. 2010.

8. Phalkey RK, Yamamoto S, Awate P, Marx M. Challenges with the implementation of an Integrated Disease Surveillance and Response (IDSR) system: systematic review of the lessons learned. Health Pol Plan. 2013:czt097.

9. Althoff T, Leskovec J, editors. Donor retention in online crowdfunding communities: A case study of donorschoose. org. Proceedings of the 24th International Conference on World Wide Web; 2015: ACM.

10. Merchant A, Ford JB, Sargeant A. 'Don't forget to say thank you': The effect of an acknowledgement on donor relationships. J Market Manag. 2010;26(7-8):593-611.

11. Royce J. The philosophy of loyalty. 1908. New York: Hafner Publishing Company; 1971.

12. Wymer W, Rundle-Thiele S. Supporter Loyalty Conceptualization, Measurement, and Outcomes. Nonprofit and Voluntary Sector Quarterly. 2016;45(1):172-91.

13. Sargeant A. Donor retention: What do we know and what can we do about it. A Report for the Association of Fundraising Professionals, Washington DC. 2008.

14. Malekzadeh E. Charitable, welfare and health institute during the reign of Reza Shah Pahlavi. Tehran: Iran History publication. [in Persian]; 2013

15. Beldad A, Snip B, van Hoof J. Generosity the second time around: Determinants of individuals' repeat donation intention. Nonprofit and Voluntary Sector Quarterly. 2012:0899764012457466.

16. Sargeant A, Hudson J. Donor retention: an exploratory study of door-to-door recruits. Int J Nonprofit Volunt Sect Mark. 2008;13(1):89-101.

17. Prendergast GP, Hak Wai Maggie C. Donors' experience of sustained charitable giving: a phenomenological study. J Consum Mark. 2013;30(2):130-9.

18. Naskrent J, Siebelt P. The influence of commitment, trust, satisfaction, and involvement on donor retention. Voluntas: Int J Volunt Nonprof Org. 2011;22(4):757-78.

19. Bennett R. Predicting the lifetime durations of donors to charities. Journal of Nonprofit \& Public Sector Marketing. 2006;15(1-2):45-67.

20. Sargeant A, Woodliffe L. Building donor loyalty: The antecedents and role of commitment in the context of charity giving. J Nonprof Pub Sect Mark. 2007;18(2):47-68.

21. Lawshe $\mathrm{CH}$. A quantitative approach to content validity1. Person Psychol. 1975;28(4):563-75.

22. Polit DF, Beck CT. The content validity index: are you sure you know what's being reported? Critique and recommendations. Res Nurs Health. 2006;29(5):489-97.

23. Aghababa s. Identification, Recruitment and Retention of Charitable Donors Model in Health Care System of Iran. Tehran, Iran: Islamic Azad University Science and Research Branch; 2015.

24. Hu Lt, Bentler PM. Cutoff criteria for fit indexes in covariance structure analysis: Conventional criteria versus new alternatives. Struct Equa Model. 1999;6(1):1-55.

25. Shelley L, Jay Polonsky M. Do charitable causes need to segment their current donor base on demographic factors?: An Australian examination. Int J Nonprofit Volunt Sect Mark. 2002;7(1):19-29.

26. Ward AM, Mckillop DG. An examination of volunteer motivation in credit unions: Informing volunteer resource management. Annal Publ Cooperat Econ. 2011;82(3):253-75.

27. Sargeant A. Relationship fundraising: How to keep donors loyal. Nonprof Manag Leader. 2001;12(2):177-92.

28. Bennett R. Regret and satisfaction as determinants of lapsed donor recommencement decisions. Int J Nonprofit Volunt Sect Mark. 2009;21(4):347-66.

29. Nguyen DD, DeVita DA, Hirschler NV, Murphy EL. Blood donor satisfaction and intention of future donation. Transfusion. 2008;48(4):7428.

30. Peachey JW, Lyras A, Cohen A, Bruening JE, Cunningham GB. Exploring the motives and retention factors of sport-for-development volunteers. Nonprofit Volunt Sect Quart. 2013:0899764013501579.

31. Echazu L, Nocetti D. Charitable giving: Altruism has no limits. J Pub Econ. 2015;125:46-53.

32. Harbaugh WT, Mayr U, Burghart DR. Neural responses to taxation and voluntary giving reveal motives for charitable donations. Science. 2007;316(5831):1622-5.

33. Glenton C, Scheel IB, Pradhan S, Lewin S, Hodgins S, Shrestha V. The female community health volunteer programme in Nepal: decision makers' perceptions of volunteerism, payment and other incentives. Soc Sci Med. 2010;70(12):1920-7. 
34. Kou X, Hayat AD, Mesch DJ, Osili UO. The Global Dynamics of Gender and Philanthropy in Membership Associations: A Study of Charitable Giving by Lions Clubs International Members. Nonprofit Volunt Sect Quart. 2013:0899764013502583.

35. Laura W, Sally H. Building donor relationships: An investigation into the use of relationship and database marketing by charity fundraisers. Serv Indust J. 2000;20(2):114-32.

36. Breman A. Give more tomorrow: Two field experiments on altruism and intertemporal choice. J Pub Econ. 2011;95(11):1349-57.

37. Yörük BK. Do Charitable Solicitations Matter? A Comparative Analysis of Fundraising Methods. Fiscal Stud. 2012;33(4):467-87.

38. Ranaweera C, Prabhu J. On the relative importance of customer satisfaction and trust as determinants of customer retention and positive word of mouth. J Target Measur Anal Mark. 2003;12(1):82-90.

39. Olsen JA, Eidem JI. An inquiry into the size of health charities: the case of Norwegian patient organisations. J Socio-Econ. 2003;32(4): 457-66. 